\title{
Irradiation augmentation of genistein-induced apoptosis in androgen-independent DU-I45 prostate cancer cells in vitro
}

\begin{abstract}
Prostate cancer is still the most common cancer diagnosed in American men after skin cancer. According to the American Cancer Society, there will be approximately 164,690 new cases and 29,430 deaths from prostate cancer for 2018. The increased difficulty in the treatment of metastasized advanced prostate cancer raises the need for the exploration of novel treatments. This study investigated the augmentation of very low dose radiation (VLDR, $20 \mathrm{mGy} / \mathrm{hr}$ ) on the treatment efficacy of genistein $(\mathrm{Gn})$ in DU-145 androgen-independent prostate cancer cells. The objective was to assess the efficacy of the combinative treatment regimen relative to the single treatments. Our data revealed that exposing DU-145 cells to VLDR for 20 minutes before treatment with $(\mathrm{Gn})$, significantly increased the therapeutic efficiency of genistein $(\mathrm{Gn})$; the combination treatment (VLDR-Gn) caused significantly more apoptotic cell death in DU-145 cells. The present data (from DU-145 cells) is in conformity with results of previous studies (on $\mathrm{LNCaP}$ and $\mathrm{PC} 3$ cells); indicating that both androgendependent and androgen-independent prostate cancer cells are sensitive to (VLDRGn) combinative regimen. This observation provides a rationale and justification for further investigation in the field of radiation-phytochemical combinative treatment.
\end{abstract}

Volume 10 Issue I - 2019

\author{
Rida Altaf,' James Kwasi Kumi-Diaka,' \\ Rolando M Branly² \\ 'Department of Biological Sciences, Charles E. Schmidt College \\ of Science, Florida Atlantic University, USA \\ ${ }^{2}$ Department of Physical Sciences, Broward College, USA
}

Correspondence: Rida Altaf, Department of Biological Sciences, Charles E. Schmidt College of Science, Florida Atlantic University, USA, Email raltaf20I4@fau.edu

Received: December 14, 2018 | Published: January 09, 2019

Keywords: Prostate cancer, Very Low Dose Radiation (VLDR), Genistein (Gn), DU-145, Apoptosis, Pyroelectricity

\section{Introduction}

Cancer is a complex disease that occurs as a result of accumulated mutations, genetic instability, and altered cellular metabolism, contributing to malignant transformation and to the initiation, growth, and maintenance/proliferation of tumors. ${ }^{1}$ Prostate cancer (PCa) is still the most common non-skin cancer among men in the United States. ${ }^{2}$ The American Cancer Society has estimated 164,690 new cases and 29,430 deaths from prostate cancer for $2018 .^{3}$ The standard treatment modalities (surgery, radio-chemotherapy, hormonal therapy) have been effective in improving the lifestyle of patients. Although the locally confined disease is treatable, treatment of the metastasized prostate cancer is still incurable with mostly guarded prognosis. ${ }^{4,5}$ The development of resistance to both radiation and chemotherapy has limited the efficacy of current therapeutic interventions for PCa. This has necessitated the search for novel and safer alternative therapeutic regimens. One way to circumvent potential treatment-induced resistance is combination treatment, using two or more therapies that may be mutually inclusive or exclusive in terms of their mechanism of actions.

There has been a focus on phytotherapy, exploring the micronutrients in plant and plant products; and the phytochemical Genistein isoflavone has been in the limelight. Genistein (4, 5, 7-trihydroxyisoflavone) is derived from soy and soy products. Increased plasma levels of isoflavone have been inversely correlated with $\mathrm{PCa}$ risk factors. In this study, we explored the therapeutic efficacy of genistein isoflavone (Gn) in combination with a very low dose of radiation (VLDR), in DU-145 hormone-independent prostate cancer cells.

\section{Genistein isoflavone}

Genistein isoflavone (Gn) (4', 5', 7-trihydroxyisoflavone) is a major dietary phytochemical in soy that has shown therapeutic potential against various human cancer cells in vitro and in animal models. ${ }^{6-8}$ The anti-cancer effects of (Gn) has been demonstrated in breast, lung, prostate, lymphoma, leukemia, and head and neck cancers. ${ }^{6,9-20}$ The specific mechanisms of (Gn) action on cancer cells have been the focus of ongoing investigations for years. Genistein is structurally related to estrogen and can, therefore, exhibit both estrogenic and anti-estrogenic activities. ${ }^{21}$ It has the ability to bind estrogenic receptors and regulate cell growth and proliferation in both androgen-dependent and androgen-independent cancer cells. ${ }^{13,22}$ In addition, (Gn) exhibits several pharmacological effects unrelated to its estrogenic properties- including: inhibition of angiogenesis and microsomal lipid peroxidation, ${ }^{21-24}$ inhibition of topoisomerase I \& II, ${ }^{6}$ inhibition of telomerase activity, ${ }^{25}$ inhibition of tyrosine kinase signaling pathway, inhibition of two cell survival proteins - Akt and NF-k $\beta ;{ }^{22}$ two anti-apoptotic proteins - Bcl-2 and Bcl-XL ${ }^{16,20,26}$ and upregulation of the pro-apoptotic proteins - Bax and $\mathrm{Bad}^{9,15-17}$, ${ }^{27,28}$ and a decrease in vascular endothelial growth factor (VEGF) correlating with a reduction in angiogenesis ${ }^{16}$ have also been reported. At low concentrations, we have been able to demonstrate that $(\mathrm{Gn})$ act as an antioxidant and at high concentration, it operates as a prooxidant. High concentrations of (Gn) create an increase in reactive oxygen species (ROS) production, which potentially leads to DNA damage and cell arrest at the G2/M cell cycle phase. ${ }^{21,29}$ There is further evidence that the mechanistic pathways through which (Gn) inhibits cancer cell growth and proliferation include: altering signal transduction pathways, cell cycle regulatory molecules, and 
activation of the caspase proteases. ${ }^{13,30}$ Another study shows the ability of genistein $(\mathrm{Gn})$ to block facilitative glucose transporter 1GLUT1 activity when it acts as a tyrosine kinase inhibitor, thereby decreasing the affinity of d-glucose for its external binding site on the cell membrane. ${ }^{31}$ Hence, it has the potential to inhibit glycolytic metabolism in cancer cells. It is, therefore, possible that one of the mechanisms through which $(\mathrm{Gn})$ induces apoptosis in cancer cells is the modulation of protein, enzymes, and biomarkers associated with angiogenesis, metabolism and tumor growth and invasion. Genistein has significantly fewer side effects and less cytotoxicity compared to standard chemo-radiotherapy. Genistein in combination with very low dose radiation (VLDR) therapy could potentially offer a safer clinical option.

\section{Very Low Dose Radiation therapy (VLDR) and Hyper- Radiosensitivity (HRS)}

Radiotherapy plays a pivotal role in standard cancer therapeutic regimen, mostly in combination with chemotherapy. The BEIR VII report defined low doses of radiation as those that do not exceed 100 mGy. ${ }^{32-34}$ Dual responses have been described in most mammalian cells at low doses of ionizing radiation. ${ }^{35,36}$ The first response prevents and/or repairs DNA damage to keep cells viable and functioning properly. The second response removes damaged cells by inducing apoptosis, terminal differentiation, and immune responses; thus eliminating mutated cells and reducing genomic instability in exposed cells/tissues. ${ }^{37,38}$ Unlike the high-power sources of X-ray radiationslinear accelerators and synchrotrons used for radiotherapy, ${ }^{39}$ recent investigations have been focused on the development of novel and cheaper low-power milli/micro/nano X-ray sources for low dose radiation..$^{40,41}$

The goals of combined treatment protocols are to improve the local control and to prevent distant micro-metastases, which may be flawed by the intrinsic radio-resistant and chemo-resistant properties of most solid tumors..$^{42}$ Studies have suggested that many cancer cells are sensitive to low doses or fractionated doses of radiation, and that (very) low doses of radiation can be used to enhance or potentiate the chemotherapeutic effect of most drugs, while at the same time decreasing the development of tumor resistance..$^{43-46}$ At low doses (LD) or very low doses (VLD) of radiation, hyper-radiosensitivity (HRS) has been demonstrated to be responsible for the increased sensitivity observed in these cells at doses less than $0.1 \mathrm{~Gy}{ }^{47,48}$ Our hypothesis is that the use of very low dose radiation (VLDR) in combination with genistein isoflavone $(\mathrm{Gn})$ will inhibit treatment-induced resistance and induce apoptotic cell death in DU-145 PCa cells at a faster rate and with significantly lower cytotoxicity.

\section{Materials and Method}

Cell line: DU-145 androgen-independent prostate cancer cell line was purchased from the American Type Culture Collection (Manassas, VA). The cells were stored at $-90{ }^{\circ} \mathrm{C}$ until used.

Reagents: MTT reagent and RPMI 1640 culture medium \& Fetal Bovine Serum (FBS) were purchased from Fisher Scientific (Waltham, MA); and Genistein (4', 5', 7-trihydroxyisoflaven) from Indoline Chemical Co. (Summerville, NJ). Genistein was constituted in DMSO (Dimethyl Sulfoxide) to obtain a stock solution of Gn-500 $\mu \mathrm{M}$. The stock solution was diluted with RPMI 1640 culture media without FBS to varying working concentrations of $\mathrm{Gn}(10 \mu \mathrm{M}, 20 \mu \mathrm{M}, 30 \mu \mathrm{M}$, $40 \mu \mathrm{M}, 50 \mu \mathrm{M}, 60 \mu \mathrm{M}$, and $80 \mu \mathrm{M})(\mathrm{Gn} 10-\mathrm{Gn} 80)$. These were stored at $4{ }^{\circ} \mathrm{C}$ until used.
Cell culture: DU-145 cells were thawed and centrifuged at 3000rpm. The pelleted cells were resuspended in RPMI 1640 culture medium with FBS, transferred into $25 \mathrm{~cm}^{2}$ culture flasks and culturedgrown/incubated at $37{ }^{\circ} \mathrm{C}$ and $5 \% \mathrm{CO}_{2}$ for 36 to $48 \mathrm{hrs}$ to achieve $80-90 \%$ confluence. Next, adherent cells were scraped with Pasteur pipette or trypsinized into monolayer suspensions. Culture medium was added and cell concentration in the flasks was determined with a hemocytometer. To culture the cells in 96-well microtiter plates (MTTP), $100 \mu \mathrm{l}$ of the suspension containing approximately $1 \times 10^{4}$ cells were transferred into each well in the MTTPs. The plates were cultured/incubated at $37^{\circ} \mathrm{C}$ and $5 \% \mathrm{CO}_{2}$ for 24 to $48 \mathrm{hrs}$ to achieve 80 $90 \%$ confluence; after which the MTTPs were grouped into A-MTTPs (for radiation) and B-MTTPs (non-radiation) to be treated with and/ or without (Gn).

\section{In vitro pyroelectric $\mathbf{X}$-ray irradiation}

DU-145 cells were cultured as previously described above. Cells in A-MTTPs were irradiated with a portable pyroelectric X-ray generator (Cool X, AMPTEX INC, Bedford, MA). Cells were exposed to a single dose of very low dose radiation (VLDR) of $20 \mathrm{mGy} /$ hour for 20 minutes. The risk and exposure to the lab were considered and a custom lead box was designed to prevent any long-term and repeated $\mathrm{X}$-ray exposure in the lab. The appropriate condition of $37^{\circ} \mathrm{C}$ and $5 \%$ $\mathrm{CO}_{2}$ was maintained within the X-ray box through a BD GasPak EZ Anaerobe Container system.

\section{MTT Assay of irradiated and non-irradiated treated DU-I45 cells}

MTT (3- [4, 5-dimethylthiazolyl-2]-2, 5-diphenyltetrazolium bromide) was utilized to assess the phytotherapeutic efficacy of genistein (Gn) on irradiated (A-MTTPs) and non-irradiated (B-MTTPs) hormone independent DU-145 cells in single and combination treatments. The DU-145 cells were cultured and treated as previously described above, and the plates were treated with $100 \mu \mathrm{l}$ of the constituted doses of (Gn10-80) as follows: i) A-MTTPs (no Gn), ii) B-MTTPs + Gn10-80 (single treatment) and, iii) A-MTTPs + Gn10-80 (combination treatment). All the plates (MTTPs) were incubated at $37{ }^{\circ} \mathrm{C}$ and $5 \% \mathrm{CO}_{2}$ and subjected to the MTT assay at $6 \mathrm{hrs}, 24 \mathrm{hrs}$, and $48 \mathrm{hrs}$ post-treatment. The assay was performed according to the manufacturer's instructions from Fisher Scientific (Waltham, MA). The absorbance was read at $570 \mathrm{~nm}$ in the Multiskan biochromatic automated microplate reader (Multiskan, DC).

The post-treatment radio-phytochemical effect on the DU-145 cells was assessed by the following determinants/equations:

I. Percentage Cell Survival Rate (\%CSR) was expressed as:

$$
\% \mathbf{C S R}=[(\mathrm{AT}-\mathrm{AB}) /(\mathrm{AC}-\mathrm{AB})] \times 100
$$

Where At $=$ Absorbance at treated, $A B=$ Absorbance at Blank, $A C=$ Absorbance at control.

II. Genistein Enhancement ratio (GER) was measured by obtaining the \%CSR for the Genistein alone and the \%CSR of the VLDR and Genistein combination as follows:

$$
\text { GER }=[\% \mathrm{CRS}(\mathrm{Gn})] /[\% \mathrm{CSR}(\mathrm{VLDR}+\mathrm{Gn})]
$$

III. Differential Growth Inhibition Rate (DGIR) between Genistein alone vs. VLDR enhanced 
Genistein combinative treatment can be expressed as:

$$
\text { DGIR }=[\% \mathrm{CRS}(\mathrm{Gn})]-[\% \mathrm{CSR}(\mathrm{VLDR}+\mathrm{Gn})]
$$

\section{Fluorescence microscopy Study}

This was to ascertain the mode of treatment-induced cell death in the DU-145 prostate cancer cells. A cocktail of two dyes (Acridine Orange and Ethidium Bromide) with different emission spectra were constituted and used to study the color differentials of the treated cells. With this specific stain, cells with light to intense orange fluorescent represent different stages of apoptosis, dark orange being the latest stage. Green would represent viable cells and red fluorescent cells would represent necrotic cell death. Briefly, DU-145 cells were initially cultured and treated as previously described in materials and methods. For the fluorescence microscope study, $50 \mu 1$ of each suspension was discharged onto microscope slides and $10 \mu$ of the dye cocktail was added and thoroughly mixed. Slides were covered lightly with coverslips and examined under a fluorescence microscope at 100x magnification. From each slide, four optical views were examined for cells and color differentials; and the number of each type/group of colored cells and the overall percent apoptosis was estimated. For each of the treatment groups, fluorescence micro photographed pictures were taken directly from under the fluorescence microscope with a Samsung Galaxy S9+ camera (Samsung: Galaxy S9 February 2018, Seoul, South Korea).

\section{Statistical analysis}

Student t-test was performed and $P$-value $\leq 0.05$ was considered significant.

\section{Results}

We investigated the effects of genistein isoflavone $(\mathrm{Gn})$ and very low dose radiation (VLDR) on androgen resistant/independent DU145 (AR-, P53-) prostate cancer cells. The results are summarized in Figures $1-4$ and Tables $1 \& 2$.

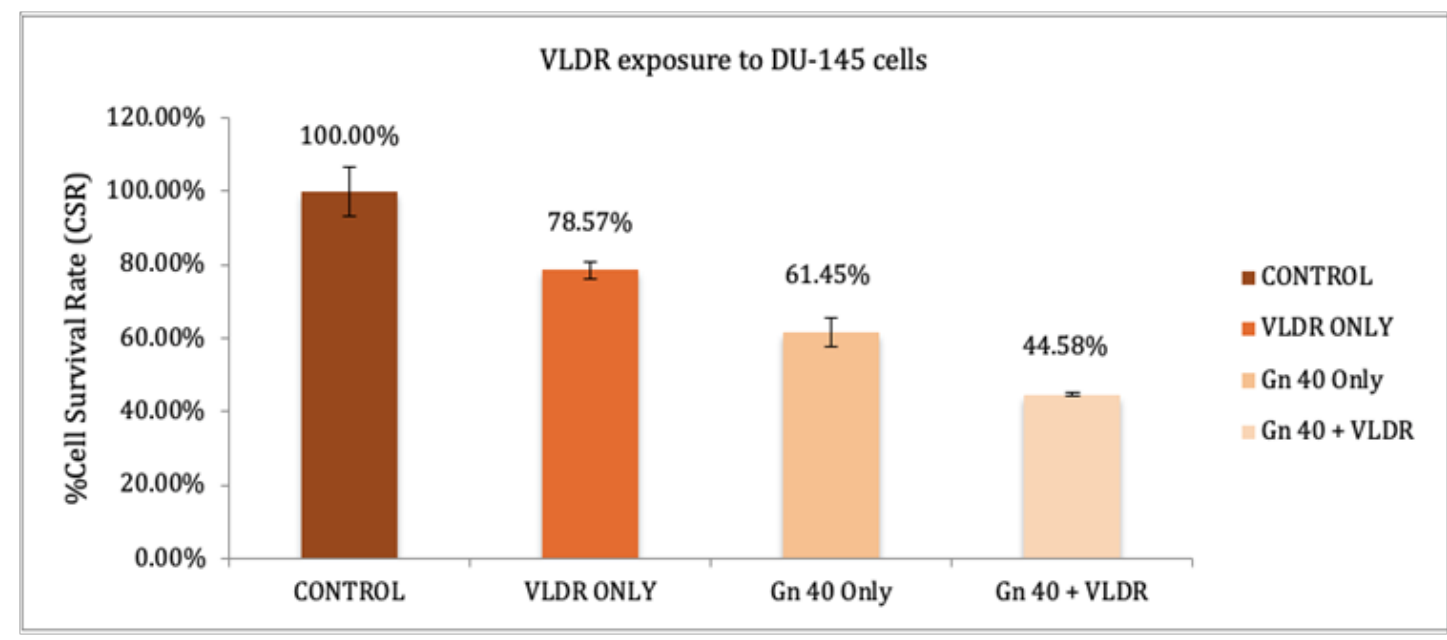

Figure I The \% CSR was assessed using MTT assay in DU-I45 prostate cancer. (\%CSR:y-axis) was plotted against the Control (no treatment),VLDR alone, Gn

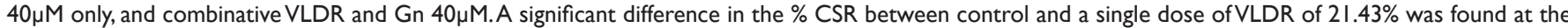
significance of $(p<0.02)$. Also, a significant difference of $16.87 \%$ was discovered with $(p<0.006)$ between $\mathrm{Gn} 40 \mu \mathrm{M}$ alone and the combination of $\mathrm{Gn} 40 \mu \mathrm{M}$ and VLDR. The results were means \pm STD of three experiments performed in triplicates.

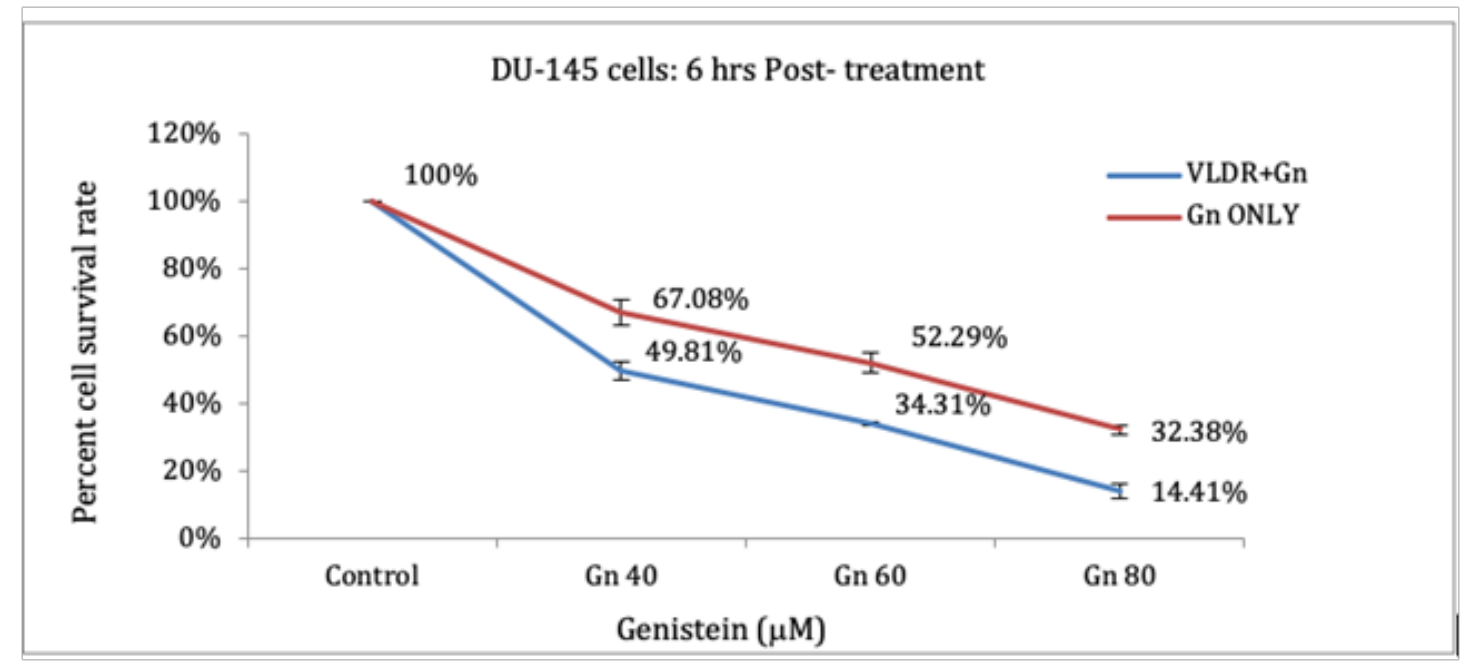

Figure 2 (a) The \%CSR was assessed with the MTT assay on DU- 145 prostate cancer cells at 6 hrs post-treatment. The (\%CSR: $y$-axis) was plotted against $(G n 40-80)$ and $(V L D R+G n 40-80)$ ( $x$-axis). The relative differences in $(\% C S R)$ were compared. Dose dependent significant decrease $(p<0.05)$ was observed.The results were means \pm STD of three experiments performed in triplicates. 


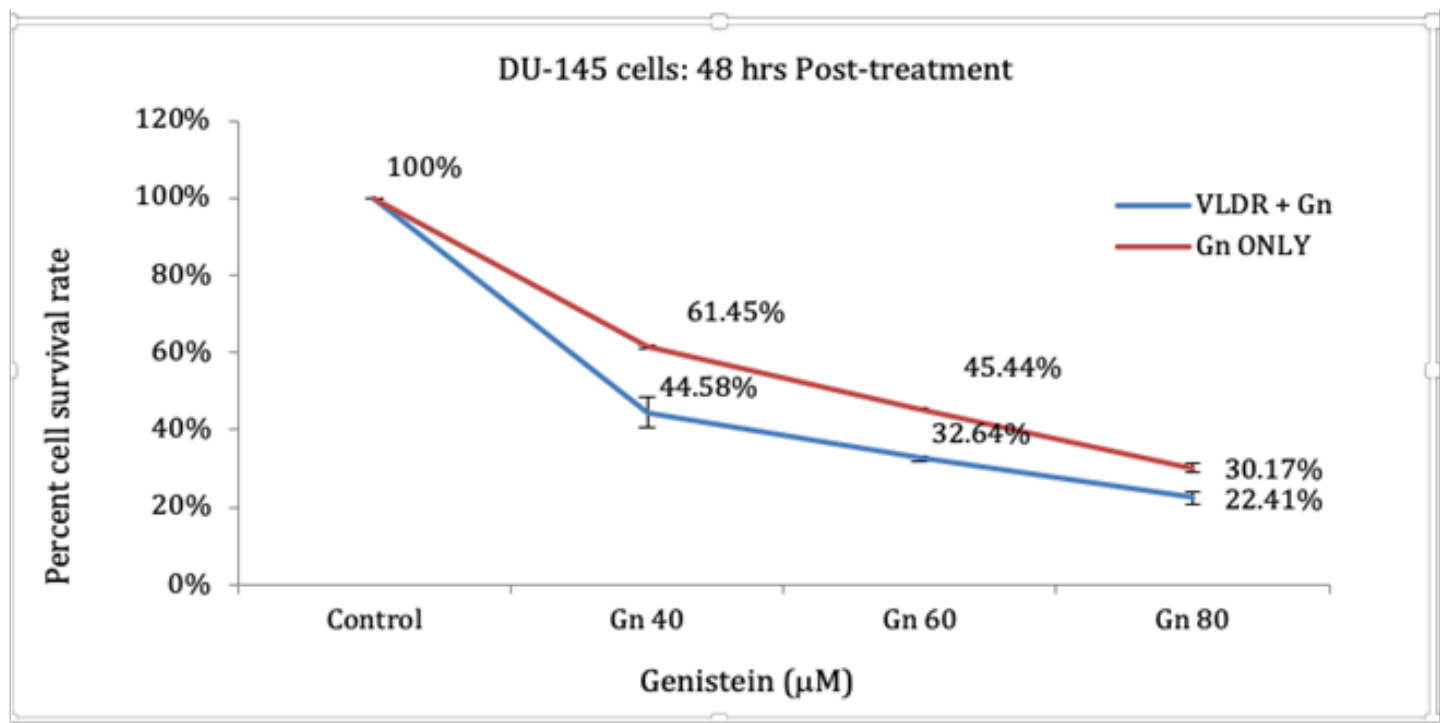

Figure 2 (b) The \%CSR was assessed with the MTT assay on DU-I 45 prostate cancer cells at 48 hrs post-treatment. The (\%CSR: $y$-axis) was plotted against $(\mathrm{Gn} 40-80)$ and (VLDR+Gn40-80) (x-axis). The relative differences in (\%CSR) were compared. Dose dependent significant decrease ( $\mathrm{P}<0.05)$ was observed. The results were means \pm STD of three experiments performed in triplicates.

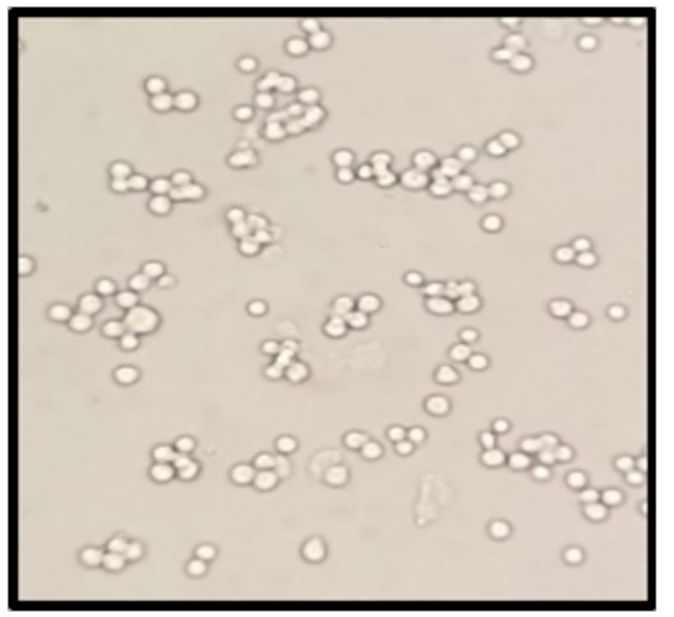

Figure 3(A) Control @ 0-hr

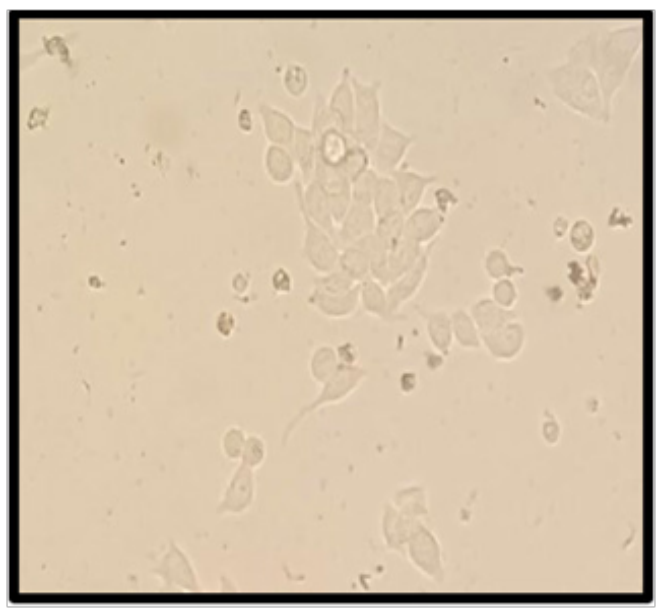

Figure 3(C) Post-VLDR at 24-hrs

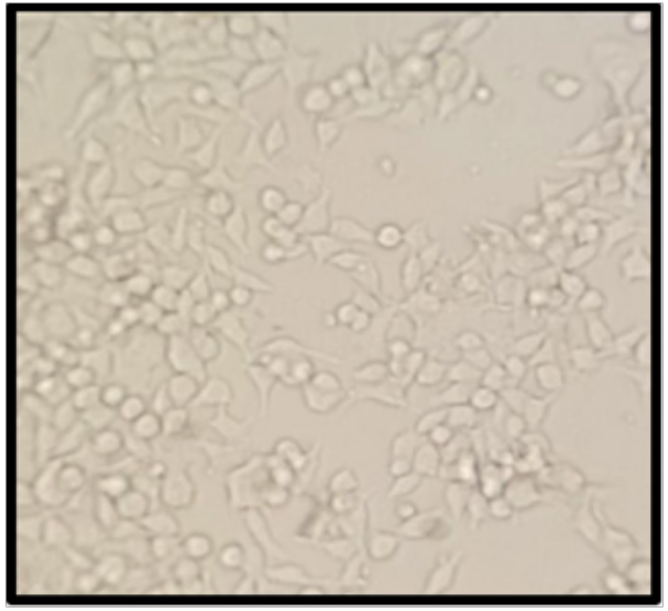

Figure 3(B) Control @ 48-hrs

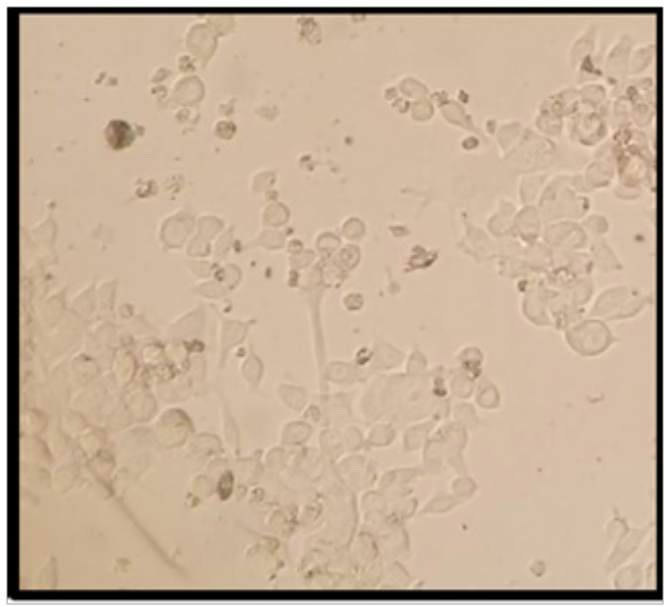

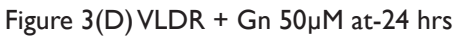

Figure 3 Photomicrographs (I00x) of DU-I45 cells treated with or without VLDR and/or Genistein. (A) Du- I45 cell line at culture day 0 . (B) DU-I45 cells at culture 48 hours prior treatment. (C) 24 hrs postVLDR treatment. (D) 24 hrs post VLDR + Gn 50 4 M combinative treatment. 

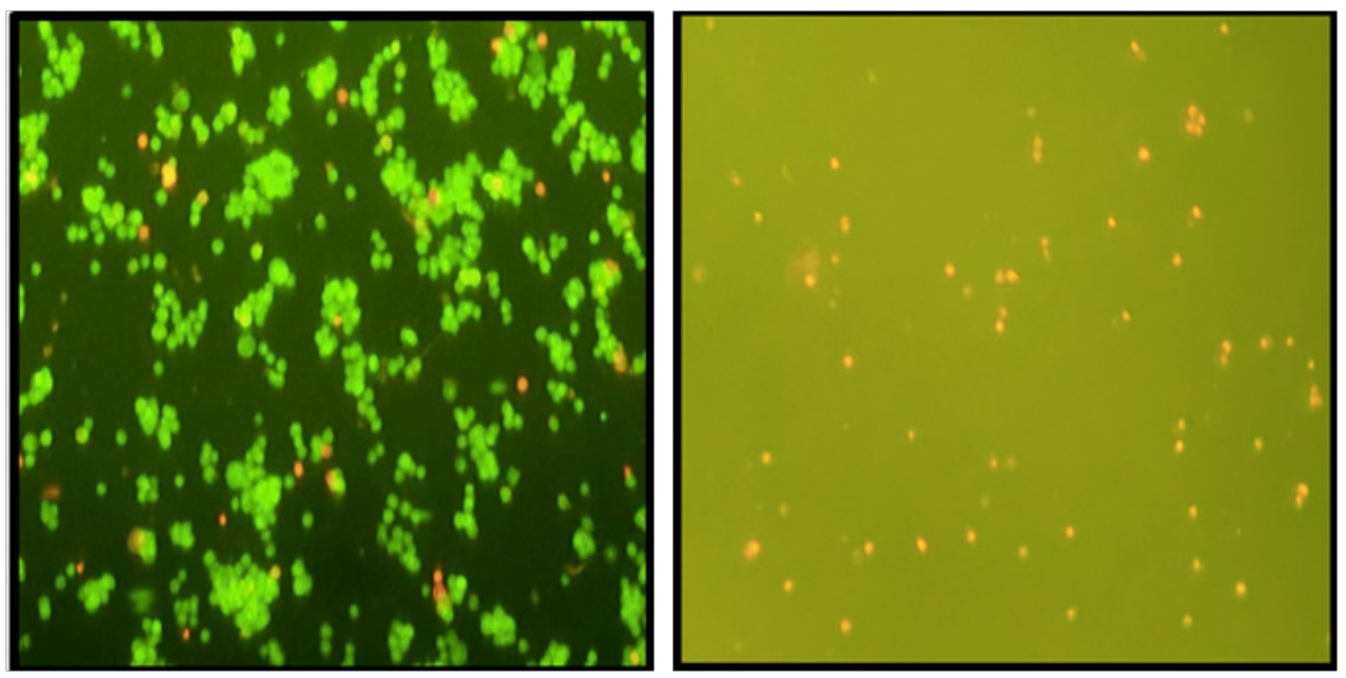

Figure 4(A) DU-I45 cells - Control

Figure 4(B) DU-I 45 cells + (VLDR Only)

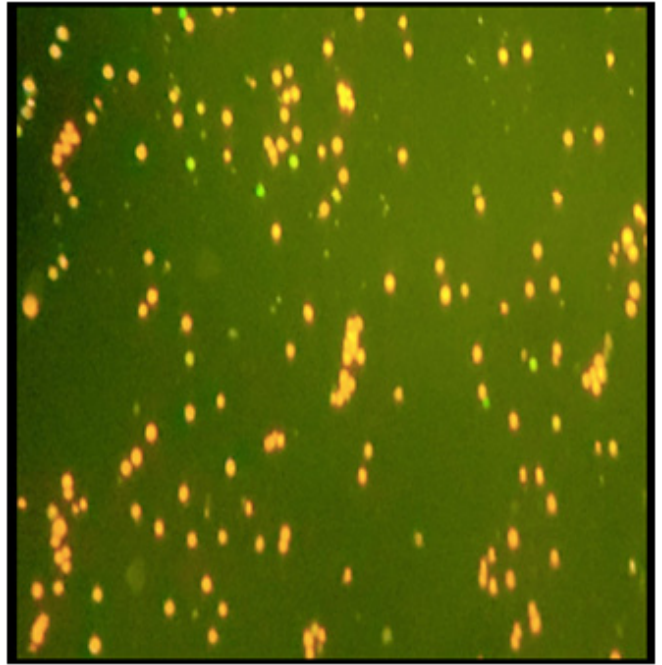

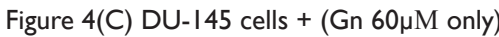

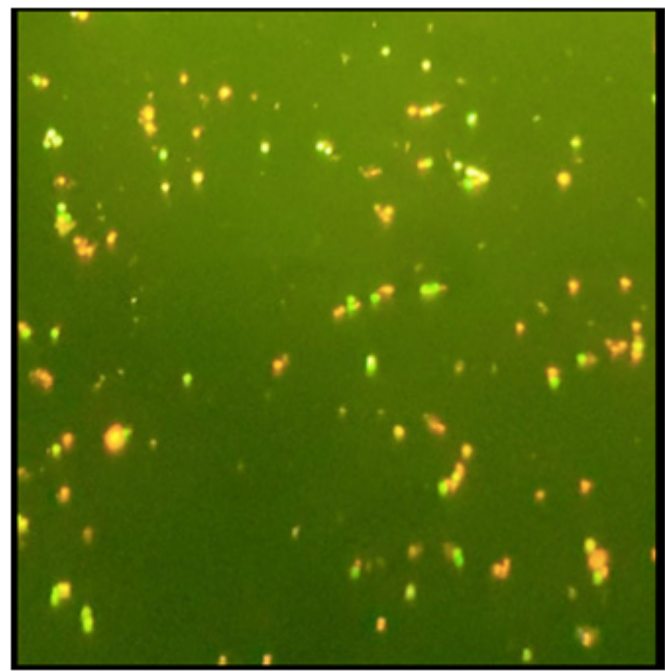

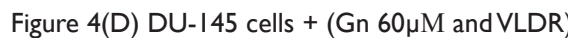

Figure 4 The morphological observation of the cell death type with Acridine Orange/ Ethidium Bromide (AO/EB) staining. DU-I45 prostate cancer cells (A) were untreated (control), (B) were treated with single treatment of VLDR only (C) were treated with a single dose of $\mathrm{Gn} 60 \mu \mathrm{M}$ only, (D) were treated with a single treatment of VLDR and a single dose of $\mathrm{Gn} 60 \mu \mathrm{M}$.

Table I VLDR (irradiation) augmentation of genistein efficacy in DU-I45 prostate cancer cells at 6 hrs post-treatment

\begin{tabular}{|c|c|c|c|c|c|c|}
\hline $\begin{array}{l}\text { Concentration } \\
\text { of } \mathrm{Gn}(\mu \mathrm{M})\end{array}$ & $\begin{array}{l}\text { Genistein } \\
\text { Only (\%CSR) }\end{array}$ & $\begin{array}{l}\text { Genistein + } \\
\text { VLDR (\%CSR) }\end{array}$ & $\begin{array}{l}\text { Differential Growth } \\
\text { Inhibition Rate (DGIR) }\end{array}$ & $\begin{array}{l}\text { DGIR } \\
\text { Ranking }\end{array}$ & $\begin{array}{l}\text { Genistein enhancement } \\
\text { ratio to VLDR (GER) }\end{array}$ & $\begin{array}{l}\text { GER } \\
\text { Ranking }\end{array}$ \\
\hline 0 & 100 & 100 & 0 & $\mathrm{~N}$ & I & $N$ \\
\hline GEN 40 & $67.08^{A}$ & $49.8 \mathrm{I}^{\mathrm{A}^{\prime}}$ & 17.27 & 3 & 1.35 & 3 \\
\hline GEN 60 & $52.29^{B}$ & $34.3 I^{B^{\prime}}$ & 17.98 & I & 1.52 & 2 \\
\hline GEN 80 & $32.38^{c}$ & $|4.4|^{C^{\prime}}$ & 17.97 & 2 & 2.24 & I \\
\hline
\end{tabular}

The DGIR was obtained from the MTT assay conducted 6 hours post-treatment of DU-I 45 cells with Gn40-80.The DGIR compares the inhibition rate of single and combinative treatment. GER provides the ratio of single to combine treatment, to examine the enhancing potency of VLDR in DU-I45 cells. Ranks were assigned for quick assessment based on doses. $N($ rank $)=$ control. One tail t-test was conducted and there was a significant difference of ( $<<0.04)$ between $A$ and $A^{\prime},\left(p^{2}<0.02\right)$ for $B$ and $B^{\prime}$ and $(p<0.01)$ for $C$ and $C^{\prime}$.There was also a significant difference between $A$ and $B(p<0.004), B$ and $C(p<0.0003), A^{\prime}$ and $B^{\prime}\left(p^{<}<0.0004\right)$ and $B^{\prime}$ and $C^{\prime}(p<0.00006)$. The results were means \pm STD of three experiments performed in triplicates. 
Table 2 VLDR (irradiation) augmentation of genistein efficacy in DU- I45 prostate cancer cells at 48 hrs post-treatment

\begin{tabular}{lllllll}
\hline $\begin{array}{l}\text { Concentration } \\
\text { of Gn }(\boldsymbol{\mu M})\end{array}$ & $\begin{array}{l}\text { Genistein } \\
\text { Only }(\% \text { CSR) }\end{array}$ & $\begin{array}{l}\text { Genistein }+ \\
\text { VLDR }(\% \text { CSR) }\end{array}$ & $\begin{array}{l}\text { Differential Growth } \\
\text { Inhibition Rate (DGIR) }\end{array}$ & $\begin{array}{l}\text { DGIR } \\
\text { Ranking }\end{array}$ & $\begin{array}{l}\text { Genistein enhancement } \\
\text { ratio to VLDR (GER). }\end{array}$ & $\begin{array}{l}\text { GER Ranking } \\
0\end{array}$ \\
\hline 100 & 100 & 0 & $\mathrm{~N}$ & 1 & $\mathrm{~N}$ \\
Gen 40 & $61.45^{\mathrm{A}}$ & $44.58^{\mathrm{A}^{\prime}}$ & 16.87 & 1 & 1.38 & 2 \\
Gen 60 & $45.44^{\mathrm{B}}$ & $32.64^{\mathrm{B}^{\prime}}$ & 12.8 & 2 & 1.39 & 1 \\
Gen 80 & $30.17^{\mathrm{C}}$ & $22.4 \mathrm{I}^{\mathrm{C}}$ & 7.76 & 3 & 1.35 & 3 \\
\hline
\end{tabular}

The DGIR was obtained from the MTT assay conducted 48 hours post-treatment of DU-I45 cells with Gn40-80. The DGIR compares the inhibition rate of single and combinative treatment. GER provides the ratio of single to combine treatment, to examine the enhancing potency of VLDR in DU- 45 cells. Ranks were assigned for quick assessment based on doses. $N$ (rank) = control. One tail t-test was conducted and there was a significant difference of ( $\mathrm{p}<0.007)$ between $A$ and $A^{\prime},\left(p^{<0.00002)}\right.$ for $B$ and $B^{\prime}$ and $(p<0.01)$ for $C$ and $C$. There was also a significant difference between $A$ and $B(p<0.000006), B$ and $C(p<0.0002)$, $A^{\prime}$ and $B^{\prime}(p<0.02)$ and $B^{\prime}$ and $C^{\prime}(p<0.002)$. The results were means $+S T D$ of three experiments performed in triplicates.

Figure 1 shows that VLDR significantly decreased the percent cell survival rate post-irradiation. There was a $21.43 \%$ decrease in DU-145 survival rate compared with the control (non-irradiated) DU145 cells. The difference was significant $(\mathrm{p}<0.02)$. Also, a significant difference of $16.87 \%$ was discovered with $(\mathrm{p}<0.006)$ between $\mathrm{Gn}$ $40 \mu \mathrm{M}$ alone and combination of $\mathrm{Gn} 40 \mu \mathrm{M}$ and VLDR.

\section{VLDR enhances the effects of genistein on DU-I45 (AR-, P53-) cell line}

A single dose of VLDR enhanced the inhibitory effects of Genistein on the androgen-independent DU-145 cells (Tables $1 \& 2$ and Figure 2). At $6 \mathrm{hr}$. post-treatment, as summarized in Table 1, there was a significant decrease in the \%CSR in various ratios in different doses. The Differential Growth Inhibition Rate (DGIR) was 17.27 ( $\mathrm{p}<$ $0.04), 17.98(\mathrm{p}<0.02)$ and $17.97(\mathrm{p}<0.01)$ in $\mathrm{Gn} 40 \mu \mathrm{M}$, Gn $60 \mu \mathrm{M}$, and Gn $80 \mu \mathrm{M}$ respectively; the Genistein Enhancement Ratio (GER) were $1.35,1.52,2.24$ in $\mathrm{Gn} 40 \mu \mathrm{M}$, Gn $60 \mu \mathrm{M}$, and $\mathrm{Gn} 80 \mu \mathrm{M}$ respectively with significant differences (Table 1). At $48 \mathrm{hr}$. post-treatment, as shown in Table 2, there was a significant decrease in the \% CSR in the various ratios in different doses, and the DGIR in Gn $40 \mu \mathrm{M}$, Gn $60 \mu \mathrm{M}$, and $\mathrm{Gn} 80 \mu \mathrm{M}$ were $16.87,12.8$, and 7.76 respectively, with significant differences (Table 2). The overall results revealed a dose and time-dependency of the Gn and VLDR in single and combination on the DU-145 cells; with significant differences in and between the parameters (Tables 1 and 2).

\section{Microscopic analysis of DU- 45 cells}

\section{Inverted microscopy examination:}

The DU-145 cells were grown and treated as previously described under materials and methods. The cells were examined under the microscope at 100x magnification. Figure 3 shows the dramatic inhibitory effect of irradiation (VLDR) and (Gn-VLDR) combination on the cells with a significant difference $(\mathrm{P}<0.05)$ between the treatment groups. Growth inhibition was dose and time-dependent. The highest growth inhibition and cell death were seen in the combination treatment at 24-hr post-treatment (Figure 3D). These microscopic observations correlate significantly with data/results in Tables 1 and 2 .

\section{Fluorescence microscopy studies}

Fluorescence microscopy was studied to determine treatmentinduced apoptotic cell death. The DU-145 cells were treated and cultured as previously written. Fluorescence microscopy stains and staining procedures were also discussed previously. Cells were examined under four optical views at $100 \mathrm{x}$ on each slide, and the percentage of each type of cells (live, apoptotic, necrotic) was roughly estimated. The fluorescence microphotographs are shown in Figures 4A-4D.

\section{Discussion}

\section{Light microscopy/ELISA}

In this study, we demonstrated the effects of priming DU-145 human prostate cancer cell line with very low dose radiation (VLDR) of $20 \mathrm{mGy} /$ hours approximately $(0.333 \mathrm{mGy} / \mathrm{min})$ prior to chemo treatment with $(\mathrm{Gn})$. The data revealed a significantly increased sensitivity of the cells to genistein isoflavone when primed with VLDR, in a dose and time-dependent manner. The combination treatment with (VLDR-Gn) exerted most significant growth inhibitory effect on the hormone-independent DU-145 cells. These results are consistent with the results of previously done studies on two different prostate cancer cells - PC3 and $\mathrm{LNCaP}^{45}$ This is the first irradiationphytochemical study on DU-145 cells, to the best of our knowledge. The $\mathrm{EC}_{50}$ of the (VLDR-Gn) combination was significantly less than the $\mathrm{EC}_{50}$ of the single treatment with VLDR or Gn; implying greater efficacy of the combination treatment and augmentation of genistein's action on DU-145 cells by irradiation with VLDR. This observation is also in conformity with that observed in PC3 (hormoneindependent) and $\mathrm{LNCaP}$ (hormone-dependent) prostate cancer cells in previous studies. ${ }^{45}$ However, the results indicated that DU-145 cells are less sensitive to the Gn and (VLDR-Gn) combination at lower doses of Gn $10 \mu \mathrm{M}$. It is critical to note that the results/observation of the microscopy studies (inverted and fluorescence) correlated significantly with the results of the MTT/-ELISA assays, indicating the consistency/validity and accuracy of the results.

\section{Fluorescence microscopy}

The mode/type of treatment-induced cell death in the DU-145 cells by the different treatment regimens is shown in Figures 4A through 4D. The fluorescence microscopy revealed that the treatment-induced growth inhibition of the DU-145 cells was mostly due to apoptotic cell death. The (VLDR-Gn) combination induced significantly higher apoptosis in the cells than the VLDR or Gn alone. The \% apoptosis at the $\mathrm{EC}_{50}$ of the (VLDR-Gn) combination is significantly higher than the $\%$ apoptosis at the $\mathrm{EC}_{50}$ of VLDR or Gn alone; implying significantly less cytotoxicity by the (VLDR-Gn) combination, and significant potential clinical implication. This present result is similar to that found in previous reports on $\mathrm{LNCaP}$ and PC3 cells. ${ }^{45}$ The same trend of apoptosis induction was seen. It is crucial to note that 
irradiation of the cells prior to treatment with genistein lowered the dose of $(\mathrm{Gn})$ with increasing efficacy of apoptosis induction in the cells. This report supports the fact that combining chemotherapy with radiation treatment could offer significant clinical benefits by decreasing cytotoxicity and subsequent side effects in patients. ${ }^{45,49,50}$ Preliminary data from limited studies in our lab revealed that (VLDRGn) combination inhibited treatment-induced resistance to apoptosis in the prostate cancer cells. Further studies are ongoing.

\section{Conclusion}

Our study demonstrated that hormone-independent DU-145 cells became more sensitive to genistein when primed with VLDR for 20 min prior to treatment in a dose-dependent manner than when treated with $(\mathrm{Gn})$ alone. The combination treatment induced significantly higher/more apoptotic cell death in the DU-145 cells at lower (Gn) concentration; implying that the (VLDR-Gn) combination treatment would be less cytotoxic. If this observation can be demonstrated in in vivo studies, the outcome will be clinically significant. Further studies are ongoing. This is the first study to the best of our knowledge to investigate the effects of VLDR on the DU-145 cells sensitivity to genistein isoflavone in vitro.

\section{Acknowledgment}

This research was partly supported by Biomedical Sciences Department in Florida Atlantic University. Special thanks to my research colleagues, Toluleke Famuyiwa, Harris D. Goldsmith, and Saheed O. Oseni for their assistance in culturing the cells and providing information as needed.

\section{Conflicts of interest}

None.

\section{References}

1. Hanahan D, Weinberg RA. Hallmarks of Cancer: The Next Generation. Cell. 2011;144(5):646-674.

2. American Cancer Society. Cancer Facts and Figures 2016. Atlanta: American Cancer Soc. 2016.

3. American Cancer Society. Cancer Facts and Figures 2018. Atlanta: American Cancer Soc. 2018.

4. Jemal A, Siegel R, Ward E, et al. Cancer statistics. CA Cancer J Clin. 2008;58(2):71-96.

5. Welch HG, Albertsen PC. Prostate cancer diagnosis and treatment after the introduction of prostate-specific antigen screening: 1986-2005. J Natl Cancer Inst. 2009;101(19):1325-1329.

6. Kumi-Diaka J. Chemosensitivity of human prostate cancer cells PC3 and LNCaP to genistein isoflavone and $\beta$-lapachone. Biol Cell. 2002;94(1):37-44.

7. Adlercreutz H, Mazur W. Phyto-estrogens and Western Diseases. Ann Med. 1997;29(2):95-120.

8. Setchell KDR, Adlercreutz H. Mammalian lignans and phyto-oestrogens: Recent studies on their formation, metabolism and biological role in health and disease. Rowland IR, eds. Role of the Gut Flora in Toxicity and Cancer: 315-345 Academic Press, London, UK, 1988.

9. Alhasan SA, Pietrasczkiwicz H, Alonso MD, et al. Genistein-induced cell cycle arrest and apoptosis in a head and neck squamous cell carcinoma cell line. Nutr Cancer. 1999;34(1):12-19.
10. Buckley AR, Buckley DJ, Gout PW, et al. Inhibition by genistein of prolactin-induced Nb2 lymphoma cell mitogenesis. Mol Cell Endocrinol. 1993;98(1):17-25.

11. Chen Wen-Fang, Ming-Hui Huang, Chi-Hung Tzang, et al. Inhibitory actions of genistein in human breast cancer (MCF-7) cells. Biochim Biophys Acta. 2003;1638(2):187-196.

12. Constantinou A, Kiguchi K, Huberman E. Induction of differentiation and DNA strand breakage in human HL-60 and K-562 leukemia cells by genistein. Cancer Res. 1990;50(9):2618-2624.

13. Kumi-Diaka J, Saddler-Shawnette S, Aller A, et al. Potential mechanism of phytochemical-induced apoptosis in human prostate adenocarcinoma cells: Therapeutic synergy of genistein and $\beta$-lapachone combination treatment. Cancer Cell Int. 2004;4(1):5-10.

14. Kumi-Diaka JK, Hassanhi M, Merchant K, et al. Influence of genistein isoflavone on matrix metalloproteinase-2 expression in prostate cancer cells. J Med Food. 2006;9(4):491-497.

15. Kumi-Diaka James, Merchant Kendra, Haces A, et al. Genisteinselenium combination induces growth arrest in prostate cancer cells. $J$ Med Food. 2010;13(4):842-50.

16. Merchant K, Kumi-Diaka J, Rathinavelu A, et al. Genistein Modulation of Immune-Associated Genes in LNCaP Prostate Cancer Cell Line. The Open Prostate Cancer Journal. 2012;5:1-7.

17. Li Y, Upadhyay S, Bhuiyan M, et al. Induction of apoptosis in breast cancer cells MDA-MB-231 by genistein. Oncogene. 1999;18(20):31663172 .

18. MR Peterson, SC Hsu, RH Scheller. A mammalian homologue of SLY1, a yeast gene required for transport from endoplasmic reticulum to Golgi. Gene. 1996;169(2):293-294.

19. Spinozzi F, Pagliacci MC, Migliorati G, et al. The natural tyrosine kinase inhibitor genistein produces cell cycle arrest and apoptosis in Jurkat Tleukemia cells. Leuk Res. 1994;18(6):431-439.

20. Tophkhane C, Yang S, Bales W, et al. Bcl-2 overexpression sensitizes $\mathrm{MCF}-7$ cells to genistein by multiple mechanisms. Int $J$ Oncol. 2007;31(4):867-874.

21. Dixon RA, Daneel F. Genistein. Phytochemistry. 2002;60(3):205-211.

22. Li Y, Sarkar FH. Inhibition of nuclear factor kappaB activation in PC3 cells by genistein is mediated via Akt signaling pathway. Clin Cancer Res. 2002;8(7):2369-2377.

23. Dalu A, Blaydes BS, Bryant CW, et al. Estrogen receptor expression in the prostate of rats treated with dietary genistein. $J$ Chromatogr B. 2002; 777:249-260.

24. Li Y, Bhuiyan M, Sarkar FH. Induction of apoptosis and inhibition of c-erbB-2 in MDA-MB-435 cells by genistein. Int J Oncol. 1999; 15(3):525-533.

25. Jagadeesh S, Kyo S, Banerjee PP. Genistein represses telomerase activity via both transcriptional and posttranslational mechanisms in human prostate cancer cells. Cancer Res. 2006;66(4):2107-2115.

26. Li Y, Che M, Bhagat S, et al. Regulation of gene expression and inhibition of experimental prostate cancer bone metastasis by dietary genistein. Neoplasia. 2004;6(4):354-363.

27. Li Z, Li J, Mo B, et al. Genistein induces G2/M cell cycle arrest via stable activation of ERK1/2 pathway in MDA-MB-231 breast cancer cells. Cell Biol Toxicol. 2008;24(5):401-409.

28. Zhou JR, Gugger ET, Tanaka T, et al. Soybean phytochemicals inhibit the growth of transplantable human prostate carcinoma and tumor angiogenesis in mice. $J$ Nutr. 1999;129(9):1628-1635. 
29. Chen Wen-Fang, Ming-Hui Huang, Chi-Hung Tzang, et al. Inhibitory actions of genistein in human breast cancer (MCF-7) cells. Biochim Biophys Acta. 2003;1638(2):187-196.

30. Agarwal C, Sharma Y, Agarwal R. Anticarcinogenic effect of a polyphenolic fraction isolated from grape seeds in human prostate carcinoma DU145 cells: modulation of mitogenic signaling and cellcycle regulators and induction of G1 arrest and apoptosis. Mol Carcinog. 2000;28(3):129-138.

31. Perez A, Ojeda P, Lorena Ojeda, et al. Hexose Transporter GLUT1 Harbors Several Distinct Regulatory Binding Sites for Flavones and Tyrphostins. Biochemistry. 2011;50(41):8834-8845.

32. National Research Council. Committee to Assess Health Risks from Exposure to Low Levels of Ionizing Radiation. Health risks from low levels of ionizing radiation: BEIR VII, Phase 2. Washington, DC: The National Academies Press, 2006.

33. BEIR VII. Committee to Assess Health Risks from Exposure to Low Levels of Ionizing Radiation. Health Risks from Exposure to Low Levels of Ionizing Radiation: Phase 2. National Academy of Sciences, National Research Council. The National Academies Press, Washington, 2006.

34. Maurice Tubiana, Ludwig Feinendegen, Chichuan Yang, et al. The linear no-threshold relationship is inconsistent with radiation biologic and experimental data. Radiology. 2009;251(1):13-22.

35. Feinendegen LE, Bond VP, Sondhaus CA. The dual response to low-dose irradiation: Induction vs prevention of DNA damage Biological Effects of Low Dose Radiation. Yamada T, eds. Excerpta Medica. International Congress Series 12-11. Elsevier, Amsterdam, London, New York, Oxford, Paris, Shannon, Tokyo: 2009;3-17.

36. Feinendegen LE, Pollycove M, Neumann RD. Whole body responses to low-level radiation exposure. New concepts in mammalian radiobiology. Experim Hematol. 2007;35(4 Suppl 1):37-46.

37. Azzam EI, de Toledo SM, Raaphorst GP, et al. Low-dose ionizing radiation decreases the frequency of neoplastic transformation to a level below the spontaneous rate in C3H 10T1/2 cells. Radiat Res. 1996;146(4):369-373.

38. Marples B, Collins SJ. Low dose hypersensitivity: past, present and future. Int J Rad Oncol Biol Phys. 2008;70(5):1310-1318.
39. Tallman R. Accelerator X-Ray Sources. Hoboken, NJ. Wiley-VCH, 2006.

40. Bizek H. The advanced photon source list of parameters. Argonne Nat Lab, Lemont, IL, Tech Rep, 1996.

41. Pfeiffer F. Hard $\mathrm{x}$-rays phase tomography with low- brilliance sources Phys Rev Let. 2007;98(10):108105.

42. Kumar R, Verma V, Jain A, et al. Synergistic chemoprotective mechanisms of dietary phytoestrogens in a select combination against prostate cancer. J Nutr Biochem. 2010;22(8):723-31.

43. Cai L, Feinendegen LE, Ikusshima T, et al. Special issue: adaptive response induced by low levels of radiation. BELLE Newsletter. $1999 ; 7(3): 2-31$.

44. Kumi-Diaka J, Oseni SO, Famuyiwa T, et al. Therapeutic Impact of Vitamin $\mathrm{C}$ on the Anticancer Activities of Genistein Isoflavone in Radiosensitized LNCaP Prostate Cancer Cells. J Cancer Prev Curr Res. 2015;2(4):1-7.

45. Oseni SO, Kumi-Diaka J, Branly R et al. Pyroelectrically Generated Very Low Dose Ionizing Radiation Potentiates the Effects of Genistein Isoflavone in Human Prostate Cancer Cells. J Cancer Prev Curr Res. 2014;1(2):1-4.

46. Oseni SO, Kumi-Diaka J, Branly R, et al. Pyroelectric Crystal Generated Very Low Dose X-ray Radiation Enhanced NQO1 Upregulation and Apoptotic Cell Death in Beta-lapachone Treated NQO1-deficient LNCaP Prostate Cancer Cells. Electronic Conference on Molecular Science, Conference Proceeding Paper. 2015;1-5.

47. Day TK, Zeng G, Hooker AM, et al. Extremely low priming doses of $\mathrm{X}$ radiation induce an adaptive response for chromosomal inversions in pKZ1 mouse prostate. Radiation Res. 2006;166(5):757-766.

48. Luckey TD. Physiological benefits from low levels of ionizing radiation Health Phys. 1982;43(6):771-789.

49. Chou T. Abstract 5398: Drug combination synergy quantification in animals and clinics using computerized combination index method. Cancer Research. 2010;70(8 Supplement):5398-5398.

50. Su Z, Yang Z, Xu Y, et al. Apoptosis, autophagy, necroptosis, and cancer metastasis. Mol cancer. 2015;14:48. 